\title{
Age-Related Alterations of Immunoreactive Pancreatic Cationic Trypsinogen in Sera from Cystic Fibrosis Patients with and without Pancreatic Insufficiency
}

\author{
P. R. DURIE, G. G. FORSTNER, K. J. GASKIN, D. J. MOORE, G. J. ClEGHORN, S. S. WONG, \\ AND M. L. COREY \\ Division of Gastroenterology, Department of Pediatrics and the Research Institute, The Hospital for Sick \\ Children and the Department of Pediatrics, University of Toronto, Toronto, Ontario, Canada
}

\begin{abstract}
Serum immunoreactive cationic trypsinogen levels were determined in 99 control subjects and 381 cystic fibrosis (CF) patients. To evaluate the status of the exocrine pancreas all $\mathrm{CF}$ patients had previously undergone fecal fat balance studies and/or pancreatic stimulation tests. Three hundred fourteen CF patients had fat malabsorption and/or had inadequate pancreatic enzyme secretion (pancreatic insufficiency) requiring oral pancreatic enzyme supplements with meals. Sixty-seven CF patients did not have fat malabsorption and/or had adequate enzyme secretion (pancreatic sufficiency) and were not receiving pancreatic enzyme supplements with meals. Mean serum trypsinogen in 99 control subjects was $31.4 \pm 14.8 \mu \mathrm{g} / \mathrm{liter}$ $( \pm 2 \mathrm{SD})$ and levels did not vary with age or sex. In CF infants $(<2 \mathrm{yr})$ with pancreatic insufficiency, mean serum trypsinogen was significantly above the non-CF values $(p$ $<0.001$ ). Ninety-one percent of the $\mathrm{CF}$ infants had elevated levels. Serum trypsinogen values in the pancreatic insufficient group declined steeply up to 5 years, reaching subnormal values by age 6 . An equation was developed which described these age-related changes very accurately. Only six CF patients with pancreatic insufficiency had serum trypsinogen levels above the $95 \%$ confidence limits of this equation. In contrast, there was no age related decline in serum trypsinogen among the $C F$ group with pancreatic sufficiency. Under $7 \mathrm{yr}$, serum trypsinogen failed to distinguish the two groups. In those over 7 yr of age, however, serum trypsinogen was significantly higher than the CF group with pancreatic insufficiency $(p<0.001)$, and $93 \%$ had values within or above the control range. In conclusion, serum trypsinogen appears to be a useful screening test for $C F$ in infancy. Between 2 and 7 yr of age this test is of little diagnostic value. After $7 \mathrm{yr}$ of age, serum trypsinogen can reliably distinguish between $\mathrm{CF}$ patients with and without pancreatic insufficiency. (Pediatr Res 20: 209213,1986 )
\end{abstract}

\section{Abbreviation}

\section{CF, cystic fibrosis}

Received May 17. 1985; accepted October 10, 1985.

Reprint requests Dr. Peter R. Durie. Division of Gastroenterology, Department of Pediatrics. The Hospital for Sick Children, 555 University Avenue, Toronto. Ontario, Canada M5G 1 X8.

Supported by a grant from the Canadian Cystic Fibrosis Foundation. D.J.M. and G.J.C. were recipients of research fellowships from the Canadian Cystic Fibrosis Foundation.
Since Crossley et al. (1) first noted elevated immunoreactive pancreatic cationic trypsinogen in sera or dried-blood spots from neonates and young infants with $\mathrm{CF}$, there has been considerable interest in utilizing this test to screen newborn infants for this common genetic condition (2-9). In addition, a number of studies have demonstrated the application of the trypsinogen radioimmunoassay as a diagnostic tool of pancreatic dysfunction in patients with a variety of clinical disorders affecting the exocrine pancreas (9-14). As a test of pancreatic function, this approach appears to have significant age-related limitations in CF patients, due to the significant elevations of serum cationic trypsinogen in infants with pancreatic insufficiency $(8,9)$. In older CF patients, however, we have shown that determination of circulating cationic trypsinogen is a useful method of distinguishing patients with steatorrhea due to pancreatic insufficiency from those with sufficient pancreatic function for normal fat absorption $(9,10)$. Levels of serum trypsinogen were normal or elevated in older CF patients with normal fat absorption and low or absent in those with steatorrhea. In order to define the exact limitations of this test, the present report evaluates the relationship between serum trypsinogen and age in a large CF population including patients with and without pancreatic insufficiency.

\section{METHODS}

Patients. We studied the majority of patients attending the $\mathrm{CF}$ Clinic, the Hospital for Sick Children, Toronto, between 1981 and 1983. Included in this report are 381 patients with CF [mean age, $11.3 \pm 12.3 \mathrm{yr}( \pm \mathrm{SD})$; range $0.1-40 \mathrm{yr}$ ], comprising 214 males and 167 females, in whom the functional status of the exocrine pancreas was known. The diagnosis of CF had previously been established by characteristic clinical manifestations as well as by elevated sweat chloride determinations ( $>60 \mathrm{mEq} /$ liter). Ninety-nine subjects [mean age, $11.6 \pm 8.9 \mathrm{yr}( \pm 1 \mathrm{SD})$; range $0.1-38 \mathrm{yr}$ ] with no clinical evidence of $\mathrm{CF}$, growth failure, metabolic, pancreatic or renal disease, served as controls. These subjects were either healthy adult volunteers or carefully selected children undergoing evaluation as inpatients. This study was approved by the Human Subject Review Committee of the Hospital for Sick Children, Toronto. Informed consent was obtained from each patient and/or parent or guardian.

Radioimmunoassay of serum pancreatic cationic trypsinogen. Random blood samples were collected from patients and controls; sera were separated by centrifugation and stored at $-70^{\circ} \mathrm{C}$ until assayed. Details of the radioimmunoassay procedure for measuring cationic trypsinogen in serum have been previously described $(15,16)$. In brief, the active site of trypsin employed as radioiodinated tracer was inactivated by tosyl lysine chloro- 
methyl ketone to prevent binding to protease inhibitors. Serum or standard cationic trypsin was added to standard radioimmunoassay buffer, followed by cationic trypsin antiserum diluted in standard buffer and ${ }^{125}$ I-tosyl lysine chloromethyl ketone-cationic trypsin tracer $(10,000 \mathrm{cpm})$ to make a final volume of $1 \mathrm{ml}$. After incubation at $4^{\circ} \mathrm{C}$ for 4 days, bound and free-labeled antigen was separated by the double antibody method using beads coated with goat antirabbit $\gamma$-globulin. Prior dilution experiments determined the optimal dilution of antiserum that was required for $50 \%$ binding of trypsin tracer.

Assessment of exocrine pancreatic function. Each of the CF patients had previously undergone fat balance studies and/or pancreatic stimulation testing to determine the need for pancreatic enzyme replacement therapy. Three- to 5-day stool collections obtained while patients were not receiving pancreatic enzyme replacement therapy were stored at $4^{\circ} \mathrm{C}$, and fecal fat content determined by the method of van der Kamer et al. (17). In patients receiving dietary medium-chain triglycerides, fecal fat content was analysed according to the method of Jeejeebhoy et al. (18). Fecal fat excretion was expressed as a percentage of mean daily fat intake, calculated by weighing food intake and reference to standard content tables.

In 93 patients, exocrine pancreatic function was also defined by the direct pancreatic stimulation test according to a previously described marker perfusion technique $(19,20)$. Following an initial collection period of $20 \mathrm{~min}$ without stimulation, duodenal secretions were aspirated over $1 \mathrm{~h}$ during continuous intravenous infusion of secretin and pancreozymin. Duodenal aspirates were analyzed for colipase, total lipase, and trypsin content by titremetric techniques (19-21) and enzyme output was then quantified using a correction factor calculated from the fractional recovery of the nonabsorbable marker $(19,20)$.

Patients were divided into two groups. Three hundred fourteen CF patients [mean age, $10.2 \pm 7.1 \mathrm{yr}( \pm 1 \mathrm{SD})$; range $0.1-31 \mathrm{yr}$ ] had steatorrhea, with fecal fat output greater than $7 \%$ of intake, or had absent or minimal enzyme output upon pancreatic stimulation testing (19). In the case of infants under 6 months of age, fecal fat loss exceeding $15 \%$ of intake was considered to be abnormal (22). These individuals were considered to have pancreatic insufficiency and were receiving oral pancreatic enzyme supplements with meals. Sixty-seven patients (mean age, $16.4 \pm$ $9.5 \mathrm{yr}$; range $0.7-40 \mathrm{yr}$ ) had fecal fat losses equal to or less than $7 \%$ of intake or following pancreatic stimulation testing had widely variable but sufficient pancreatic enzyme output for normal fat absorption (19). None of these individuals was receiving pancreatic enzyme supplements with meals. The term "pancreatic sufficiency" will be used to describe the group of CF patients with sufficient pancreatic function for normal fat absorption.

Data analysis. All the serum trypsinogen test data were incorporated into the Hospital for Sick Children computerized data base which contains retrospective clinical and diagnostic data on all $\mathrm{CF}$ patients as well as prospectively recorded longitudinal data obtained since inception of this program in 1977 (23).

Analysis of the data focused on: 1) the relationship between serum trypsinogen and age for CF patients with and without pancreatic insufficiency; 2) the relationship of elevated or decreased serum trypsinogen to malabsorption, age of diagnosis, and pulmonary function; 3) age-specific differences in levels of serum trypsinogen between males and females.

Computations were done separately for patients with and without pancreatic insufficiency and for males and females separately and combined. Means and SDs for serum trypsinogen levels were computed for each year of age in the control subjects and in the patients with CF. Since the relationship of serum trypsinogen with age in the CF patients with pancreatic insufficiency was clearly nonlinear, we sought a suitable transformation of the data points that would also account for the decreasing variance with increasing age. Since the data suggested an exponential or hyperbolic model, a number of logarithmic and recip- rocal transformations, alone and in combination, were attempted and the resulting data points plotted on computer graphs. The only plots that displayed a linear pattern with roughly homogenous variance were of the form: $\log (Y+D)=B /(X+C)+A$ where: $\mathrm{Y}=$ serum trypsinogen level; $\mathrm{X}=$ age $\mathrm{D}=\mathrm{a}$ constant number added to every $\mathrm{Y}$ to avoid logarithms of zero; $\mathrm{C}=\mathrm{a}$ constant number added to every $\mathrm{X}$ to avoid division by zero; $\mathrm{B}$ = slope, $\mathrm{A}=$ intercept $\}$ least squares linear regression of $\log$ $(\mathrm{Y}+\mathrm{D})$ on $\mathrm{l} /(\mathrm{X}+\mathrm{C})$.

Nonlinear least squares regression was used to find optimal combinations of A, B, C, and D. When stable values for D and $C$ had been selected, the linear least squares estimates for $A$ and $B$ and the confidence levels about the fitted equation were used to describe the population pattern.

In order to test the stability of the resultant model, the pancreatic insufficient group was divided into two. Separate equations and confidence limits were computed for the 159 patients tested before December 1981 and the 155 patients tested after the date. The ability of each model to classify individuals in the other half was evaluated. Separate regression equations were also computed for males and females. All computer processing and analysis was done using the Statistical Analysis System (24).

\section{RESULTS}

In the 99 control subjects without $\mathrm{CF}$, serum trypsinogen was $31.4 \pm 7.4 \mu \mathrm{g} /$ liter $($ mean $\pm \mathrm{SD}$ ) with a range of $15.1-61.3 \mu \mathrm{g} /$ liter. Individual values were not related to age or sex, and therefore standard limits have been taken as $2 \mathrm{SD}$ from the mean (16.6-46.2 $\mu \mathrm{g} / \mathrm{liter})$. Figure 1 shows serum trypsinogen values plotted against age for the $314 \mathrm{CF}$ patients with pancreatic insufficiency. Serum trypsinogen (mean $\pm \mathrm{SD}$ ) was significantly elevated above mean values for non-CF controls in 37 infants under $1 \mathrm{yr}$ of age $(249.7 \pm 162.6 \mu \mathrm{g} /$ liter, $p<0.001)$ and in six infants between 1 and $2 \mathrm{yr}$ of age $(123.1+85.7 \mu \mathrm{g} /$ liter, $p<$ 0.01 ). Mean serum trypsinogen decreased steeply with age up to $5 \mathrm{yr}$, reaching subnormal values at age 6 , and this was followed by a much slower decline in values into adolescence and adulthood. The curved lines in Figure 1 show the least squares mean and $95 \%$ confidence limits obtained from the linear regression of the variables transformed as described in "Methods." The derived equation $\left[\log _{e}(\mathrm{Y}+1)=28.9 /(\mathrm{X}+5)-0.257\right]$ describes the population of $\mathrm{CF}$ patients with pancreatic insufficiency very accurately, reflecting the pattern seen if mean $\pm 2 \mathrm{SD}$ are plotted for each year of age. However, the equation provides continuous predictive capability at all ages and minimizes the effects of outlier values at a specific age. Separate equations for each sequentially tested half of the population were virtually identical indicating the mathematical and chronological stability of the model. Only six individuals with pancreatic insufficiency had serum trypsinogen levels above the $95 \%$ confidence limits of the derived equation, while three patients had levels below these limits.

Contrasting results were obtained in the group of CF patients with pancreatic sufficiency. Figure 2 shows a scatter plot of individual serum trypsinogen levels in the patients with pancreatic sufficiency plotted against age and superimposed upon the mathematically derived mean and $95 \%$ confidence limits for the CF patients with pancreatic insufficiency. Under $7 \mathrm{yr}$ of age, serum trypsinogen levels failed to distinguish the two groups of patients. However, after $7 \mathrm{yr}$ of age, serum trypsinogen in the pancreatic sufficient patients was significantly above values for the larger group with pancreatic insufficiency $(p<0.01)$. Only six patients with pancreatic sufficiency had serum trypsinogen values within the $95 \%$ confidence limits of the derived equation for the group with pancreatic insufficiency. Data are sparse in the young patients ( $n=2<2 \mathrm{yr}, n=10<5 \mathrm{yr}$ ); thus, we are unable to determine whether or not elevated serum trypsinogen is also a consistent characteristic of young CF patients with pancreatic sufficiency. 


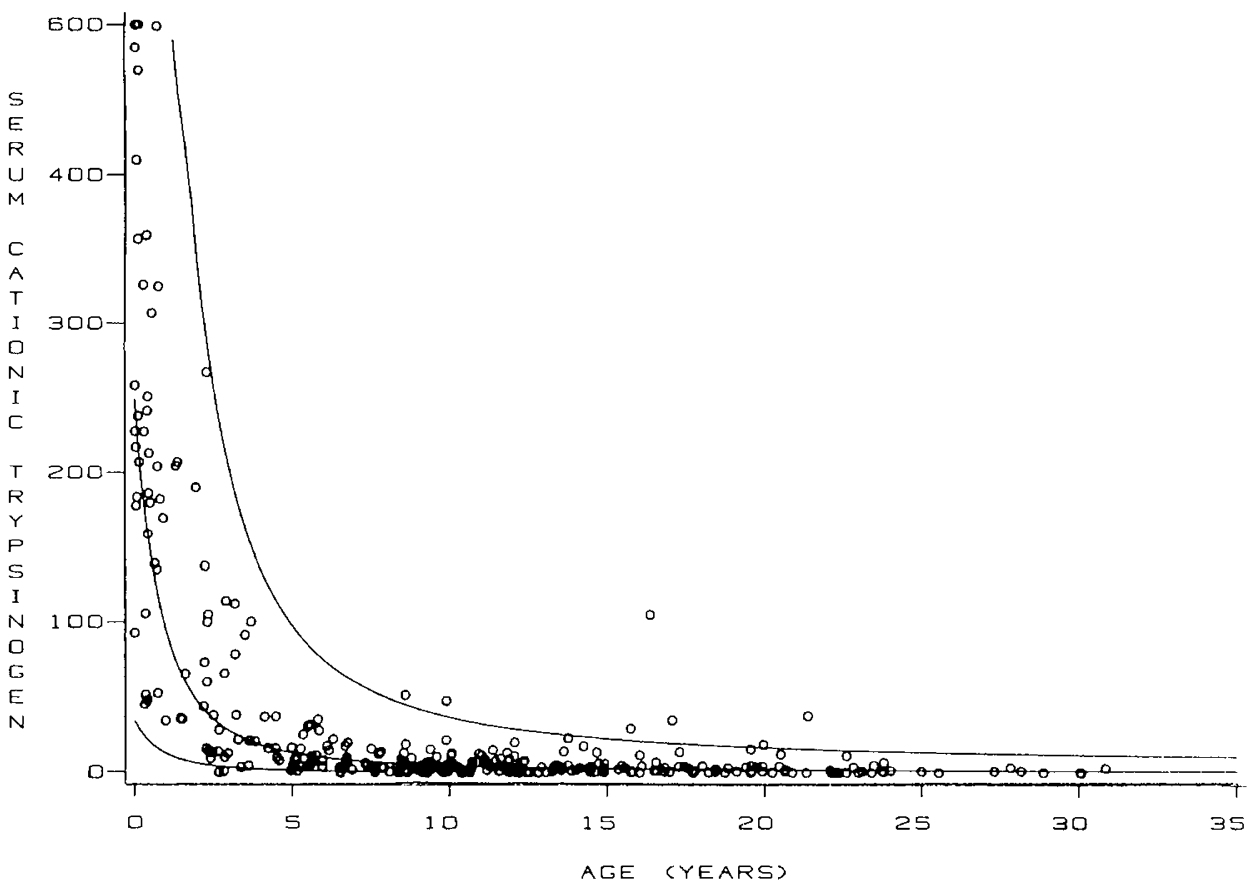

Fig. 1. Individual serum trypsinogen values ( $\mu \mathrm{g} / \mathrm{liter}$ ), plotted against age, for $314 \mathrm{CF}$ patients with pancreatic insufficiency. The least squares mean and $95 \%$ confidence limits of the derived equation are shown (see "Methods"). Only six patients with pancreatic insufficiency had serum trypsinogen levels above the $95 \%$ confidence limits while three had levels below these limits.

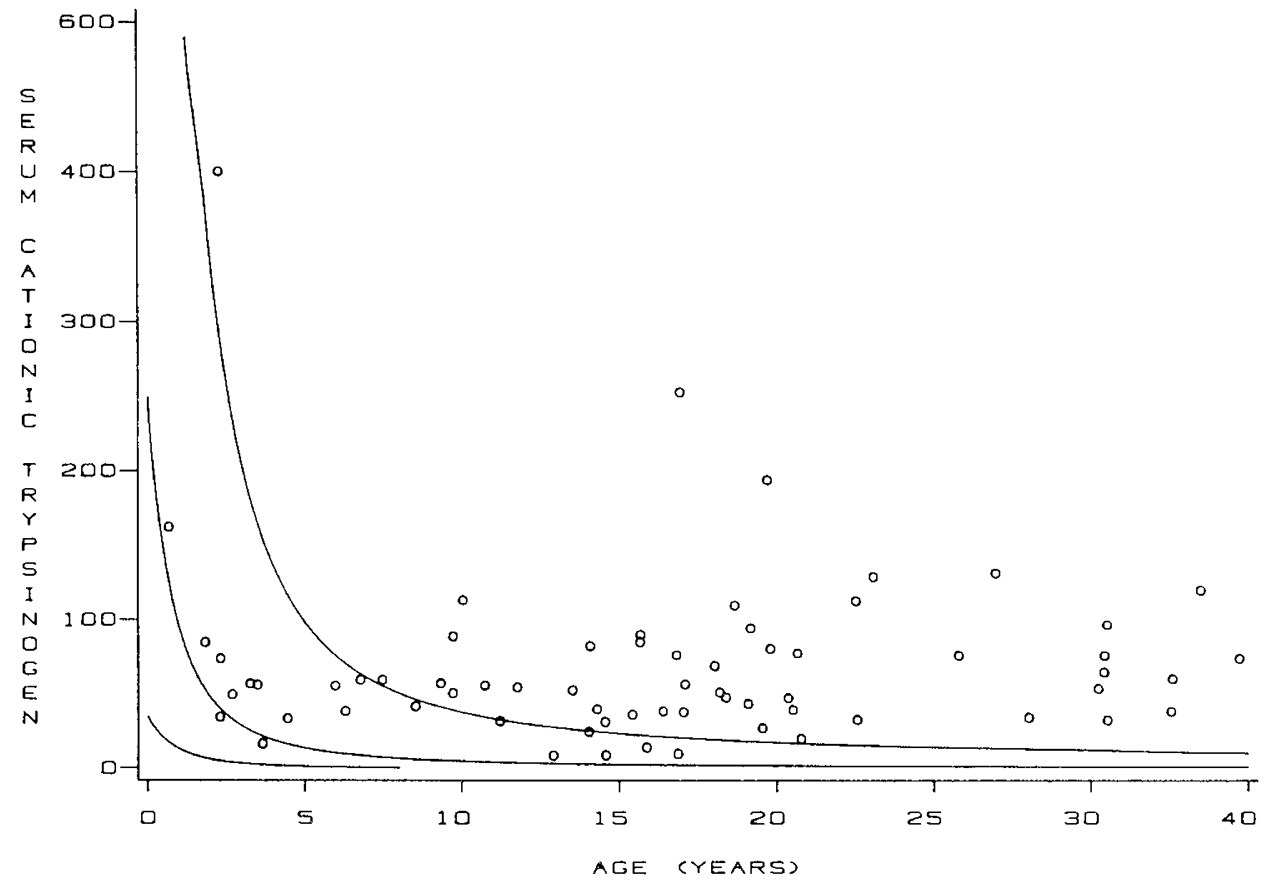

Fig. 2. Individual serum trypsinogen values ( $\mu \mathrm{g} /$ liter), plotted against age, for the $67 \mathrm{CF}$ patients with pancreatic sufficiency, superimposed on the mathematically derived equation for the $\mathrm{CF}$ group with pancreatic insufficiency. Under $7 \mathrm{yr}$ of age, serum trypsinogen failed to distinguish the two groups of patients. After $7 \mathrm{yr}$ of age, however, serum trypsinogen was significantly above the $95 \%$ confidence limits for the group with pancreatic insufficiency $(p<0.01)$. Only six older patients with pancreatic sufficiency had serum trypsinogen values within the $95 \%$ confidence limits of the values for those with pancreatic insufficiency.

Table 1 shows the distribution of serum trypsinogen among the $\mathrm{CF}$ patients with respect to the limits for the non-CF controls. Ninety-one percent of the pancreatic insufficient patients under age 2 had elevated levels while $94 \%$ over age 7 had reduced levels. Age 2-6 appeared to be a transition period between these two extremes. Ninety-three percent of the CF patients with pancreatic sufficiency aged 7 and over had trypsinogen levels within or above the non-CF range. A similar pattern was noted in the pancreatic sufficient CF patients under 7 yr but numbers were too small to draw any conclusions.

Equations of serum trypsinogen against age were derived separately for CF males and females. In each case, males and females produced identical results, although there were fewer long-term female survivors, particularly in the group with malabsorption, 
which is consistent with previous reports from our center of the poor survival patterns among older CF females (23). Table 2 shows the similarity of mean trypsinogen levels in males and females over 7 in both the pancreatic sufficient and insufficient groups. The larger number of males and the higher mean age of the patients with pancreatic sufficiency are characteristic of this CF population $(23,25)$. In Table 3 some clinical characteristics of the two CF groups are compared with reference to the normal limits of serum trypsinogen. Typically, the group with pancreatic sufficiency was older, was diagnosed later, and had better pulmonary function considering age than the group with malabsorption. The four patients with pancreatic sufficiency and reduced serum trypsinogen tended to be younger and were diagnosed earlier than the average for their group. There was no other suggestion of a relationship between the level of serum trypsinogen and the age of diagnosis or pulmonary function.

\section{DISCUSSION}

By studying a large CF population over a wide age spectrum, and including patients with a wide range of pancreatic function, a number of important observation can be made. In the vast majority of infants with pancreatic insufficiency, serum trypsinogen levels were greatly elevated. This is consistent with previous data from a number of investigations (1-7) including our own $(8,9)$. From early infancy, there was a consistent and predictable decline in serum trypsinogen in the pancreatic insufficent group, reaching subnormal values by age 5-6 yr, followed by an insignificant decline thereafter. In contrast, there was no obvious agerelated decline in serum trypsinogen among the CF group with pancreatic sufficiency. In fact, many of the older pancreatic sufficient patients had values well above the normal range for non-CF controls.

Previously, it has been reported that the elevated serum trypsinogen levels observed in the newborn period declined to normal

Table 1. Frequency (\%) of CF patients in three age groups with serum trypsinogen levels below, within, or above the non-CF range (16.6-46.2 $\mathrm{gg} /$ liter)

\begin{tabular}{cccccccc} 
& \multicolumn{3}{c}{ Pancreatic insufficiency } & & \multicolumn{3}{c}{ Pancreatic sufficiency } \\
\cline { 2 - 4 } \cline { 5 - 7 } Age $(\mathrm{yr})$ & Below & Normal & Above & & Below & Normal & Above \\
\hline$<2$ & $0(0)$ & $4(9)$ & $39(91)$ & & $0(0)$ & $0(0)$ & $2(100)$ \\
$2-6$ & $40(55)$ & $20(28)$ & $12(17)$ & & $1(9)$ & $3(27)$ & $7(64)$ \\
$\geq 7$ & $187(94)$ & $9(4.5)$ & $3(1.5)$ & $4(7)$ & $16(30)$ & $34(63)$ \\
\hline
\end{tabular}

or subnormal levels very rapidly, often within the first few weeks of life $(26,27)$. The considerable number of patient data points obtained in this study shows that this is not the case, since more than $90 \%$ of CF infants with pancreatic insufficiency had significantly elevated serum trypsinogen levels up to $2 \mathrm{yr}$ of age. The observed decline in serum trypsinogen over the first 5 yr of life appears to be extremely consistent within the pancreatic insufficient group, as the vast majority of the levels were within the limits of a mathematically derived equation developed to enable continuous predictive capability. Since this observation was based on cross-sectional data, longitudinal evaluation of serum trypsinogen levels in a large number of CF infants will be needed to confirm these findings. It has also been suggested that $\mathrm{CF}$ infants with pancreatic sufficiency may not have consistently elevated serum levels of immunoreactive trypsinogen, which in turn would reduce the usefulness of this technique for population screening purposes (27). Only two CF patients with pancreatic sufficiency in our group were under $2 \mathrm{yr}$ of age and both had elevated serum trypsinogen levels. Obviously, our current data are too limited to determine whether or not elevated serum trypsinogen is indeed a consistent finding in the young CF infant with some preservation of pancreatic function. It may be difficult to obtain sufficient information to permit conclusive analysis of this observation because CF patients with pancreatic sufficiency are generally diagnosed at an older age due to milder clinical symptoms (25).

We have also been able to define the limitations of this technique as a test of exocrine pancreatic function in older CF patients. Under 6 yr of age, serum trypsinogen cannot distinguish CF patients with pancreatic insufficiency from those with pancreatic sufficiency, since a high percentage of the patients from both groups had normal or elevated serum trypsinogen values. After 7 yr of age, serum trypsinogen accurately distinguished patients with pancreatic insufficiency from those with pancreatic sufficiency. These data, therefore, confirm our previous observation in a limited number of patients $(9,10)$ that measurement of serum trypsinogen is a useful screening test of exocrine pancreatic function in older CF patients. We have now extended this observation by delineating the precise age limitations of the test.

The mechanism of entry of pancreatic trypsinogen into the circulation remains unknown. The fact that this enzyme appears to be present in the zymogen form in measurable amounts in normal individuals (15), suggests direct entry into the circulation from the pancreas rather than via intestinal reabsorption. The high serum levels of trypsinogen in CF infants with steatorrhea

Table 2. Mean serum trypsinogen ( $\mu \mathrm{g} / \mathrm{liter})$ in $C F$ males and females aged $7 \mathrm{yr}$ and older

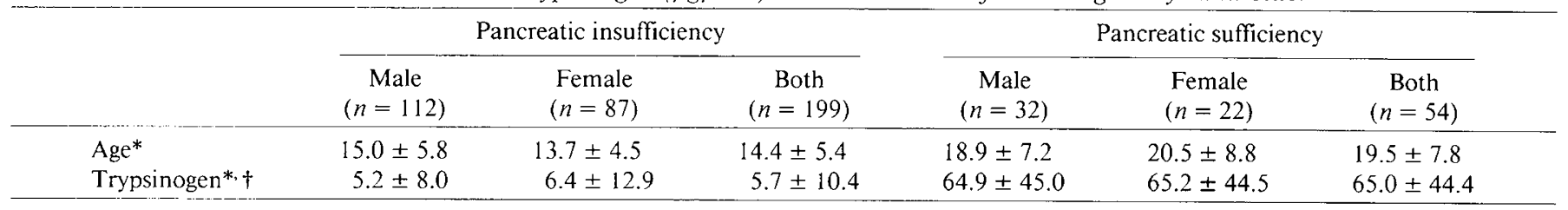

$*$ Mean \pm 1 SD.

$\dagger$ Significantly different from non-CF range $(p<0.01)$.

Table 3. Serum trypsinogen ( $\mu \mathrm{g} /$ liter) in CF patients seven years or older compared with age, age at diagnosis, and pulmonary function ( $F E V_{1} \%$ of predicted) classified according to serum trysinogen below, within, or above the non-CF range

\begin{tabular}{|c|c|c|c|c|c|c|}
\hline \multirow[t]{2}{*}{ Serum trypsinogen } & \multicolumn{3}{|c|}{ Pancreatic insufficiency } & \multicolumn{3}{|c|}{ Pancreatic sufficiency } \\
\hline & $\begin{array}{c}\text { Below } \\
(n=187)\end{array}$ & $\begin{array}{c}\text { Normal } \\
(n=9)\end{array}$ & $\begin{array}{l}\text { Above } \\
(n=3)\end{array}$ & $\begin{array}{c}\text { Below } \\
(n=4)\end{array}$ & $\begin{array}{l}\text { Normal } \\
(n=16)\end{array}$ & $\begin{array}{c}\text { Above } \\
(n=34)\end{array}$ \\
\hline Mean age* & $14.4 \pm 5.5$ & $14.7 \pm 4.3$ & $11.6 \pm 4.2$ & $15.0 \pm 1.7$ & $29.3 \pm 7.1$ & $20.2 \pm 8.5$ \\
\hline Age at diagnosis* & $3.0 \pm 4.6$ & $2.8 \pm 3.4$ & $1.4 \pm 1.1$ & $2.6 \pm 3.7$ & $12.4 \pm 9.1$ & $9.2 \pm 7.9$ \\
\hline $\mathrm{FEV}_{1} \%$ of pred* & $75 \pm 26$ & $74 \pm 23$ & $81 \pm 26$ & $93 \pm 21$ & $85 \pm 23$ & $77 \pm 25$ \\
\hline
\end{tabular}

* Mean \pm 1 SD. 
may be due to regurgitation directly into the circulation from functional pancreatic acinar tissue proximal to obstructed pancreatic ducts. Quantitative pancreatic stimulation tests performed on some of these infants revealed little or no secretion of pancreatic enzymes into the duodenum with simultaneous elevated concentrations of trypsinogen in the circulation (9). The age-related decline of circulating trypsinogen in $\mathrm{CF}$ infants with pancreatic insufficiency suggests ongoing destruction of functional acinar tissue. Elevated serum trypsinogen levels in older CF patients with pancreatic sufficiency may well be due to similar obstructive mechanisms, since our recent studies have shown that $\mathrm{CF}$ patients with a wide range of pancreatic function, including those with normal enzyme output secrete significantly less water from the pancreas than non-CF subjects (28). Pancreatic protein concentrations in these patients are significantly higher than non-CF controls at all levels of pancreatic acinar function. Since hyperconcentrated protein secretions appear to result from diminished fluid output we have speculated that any minor depressions in water flow could lead to stasis, protein precipitation, and ductal plugging. This process could, in turn, be responsible for increased regurgitation of pancreatic enzymes into the circulation. Alternatively, high serum trypsinogen levels could be due, at least in part, to hyperconcentration of this enzyme within the pancreatic ducts or acini resulting in more rapid diffusion into the circulation (29).

Some authors have suggested that exocrine pancreatic function in $\mathrm{CF}$ patients with pancreatic sufficiency may deteriorate with time (30). Although this observation is not well documented, the fact that some of these patients are prone to recurrent pancreatitis suggests ongoing pancreatic damage can occur (31). Also, in our experience, a number of CF patients who clearly had normal fat absorption at diagnosis, have developed steatorrhea upon repeating fat balance studies in subsequent years (unpublished observation). If, indeed, some of these patients are losing exocrine pancreatic function with time, one would expect the serum levels of trypsinogen to decline with age, in a similar manner, but at a later stage than the patients with pancreatic insufficiency. Since our current cross-sectional data cannot answer this question, longitudinal evaluation of serum trypsinogen data in these patients in conjunction with direct tests of exocrine pancreatic function is in progress.

Serum cationic trypsinogen may also be abnormal in patients with clinical disorders unrelated to CF. Elevated serum levels of trypsinogen are known to occur in patients with acute pancreatitis (32) and during acute malnutrition in infancy (33). Also, since the primary route of excretion of cationic trypsinogen is via glomerular filtration, renal impairment will result in greatly elevated values (34). Low serum trypsinogen levels are associated with patients with pancreatic insufficiency including adults with chronic pancreatitis (12-14) and children with primary defects of exocrine pancreatic function such as Shwachman syndrome (9).

In conclusion, provided the age-related limitations are recognized, determination of cationic trypsinogen in sera of CF patients is of some value both as a diagnostic screening technique in infancy and also as a test of exocrine pancreatic dysfunction in the older age group. Our data have clearly defined these agerelated limitations. Future studies will evaluate longitudinally, alterations in serum trypsinogen in CF patients with pancreatic sufficiency in conjunction with a direct test of exocrine pancreatic function, in order to determine whether or not a significant number of these patients are experiencing deterioration of exocrine pancreatic function with advancing age.

\section{REFERENCES}

1. Crossley JR, Elliott RB, Smith PA 1979 Dried-blood spot screening for cystic fibrosis in the newborn. Lancet 1:472-474

2. Dandona P. Hodson M. Bell J. Ramdial L, Beldon I, Batten JC 1979 Serum immunoreactive trypsin concentrations in cystic fibrosis. Lancet 1:1032

3. King DN, Heeley AF, Walsh MP. Kuzemko JA 1979 Sensitive trypsin assay for dried blood spots as a screening procedure for early detection of cystic fibrosis. Lancet 2:1217-1219

4. Kirby LT, Applegarth DA, Davidson AGF, Wong LTK, Hardwick DF 1981 Use of dried blood spot specimens as a screening procedure for early detection of cystic fibrosis. Clin Chem 27:678-680

5. Crossley JR, Smith PA, Edgar BW, Gluckman PD, Elliott RB 1981 Neonatal screening for cystic fibrosis using immunoreactive trypsin assay in dried blood spots. Clin Chim Acta 113:111-121

6. Wilcken B, Brown ARD, Urwin R, Brown DA 1983 Cystic Fibrosis Screening by dried blood spot trypsin assay: results in 75,000 newborn infants. J Pediatr 102:383-387

7. Heeley AF, Heeley ME, King DN, Kuzemko JA, Walsh MP 1982 Screening for cystic fibrosis by dried spot trypsin assay. Arch Dis Child 57:18-21

8. Cleghorn G, Benjamin L, Corey M, Forstner G, Dati F, Durie P 1985 Age related alterations of immunoreactive pancreatic lipase and cationic trypsinogen in young children with cystic fibrosis. J Pediatr 107:377-381

9. Durie PR, Largman C, Brodrick JW, Johnson JH, Gaskin KJ, Forstner GG, Geokas MC 1981 Plasma immunoreactive pancreatic cationic trypsinogen in cystic fibrosis: a sensitive indicator of exocrine pancreatic dysfunction. Pediatr Res 15:1351-1355

10. Cleghorn GJ, Benjamin L, Forstner GG, Dati F, Durie PR 1986 Serum immunoreactive pancreatic lipase and cationic trypsinogen in the assessment of pancreatic function in older patients with cystic fibrosis. Pediatrics (in press)

11. Duffy MJ, McGarry Y, Hynes N, Duffy GJ, Tobin M, Fitzgerald MX 1980 Decreased immunoreactive trypsin levels in sera from cystic fibrosis patients. Clin Chim Acta 103:233-235

12. Adrian TE, Besterman HS, Mallinson CN, Pera A, Redshaw MR, Wood TP, Bloom SR 1979 Plasma trypsin in chronic pancreatitis and pancreatic adenocarcinoma. Clin Chim Acta 97:205-209

13. Andriulli A, Masoero G, Felder M, Vantini I, Petrillo M, Cavallini G, Porro GB, Dobrilla G, Verme G 1980 Circulating trypsin-like immunoreactivity in chronic pancreatitis. Dig Dis Sci 26:532-537

14. Jacobson DG, Curington C, Connery K, Toskes PP 1984 Trypsin-like immunoreactivity as a test for pancreatic insufficiency. N Engl J Med 310:13071309

15. Geokas MC, Largman C, Brodrick JW, Johnson JH 1979 Determination of human pancreatic cationic trypsinogen in serum by radioimmunoassay. Am J Physiol 263:E77-83

16. Largman C, Brodrick JW, Geokas MC 1981 Radioimmunoassay determination of circulating pancreatic endopeptidases. Methods Enzymol 74:272-290

17. van der Kamer JH, ten Bokkel Huinick H, Weyer HA 1949 Rapid method for determination of fat in feces. J Biol Chem 177:347-352

18. Jeejeebhoy KN, Ahmad S, Kozak G 1970 Determination of fecal fats containing both medium and long-chain triglycerides and fatty acids. Clin Biochem $3: 157-163$

19. Gaskin KJ, Durie PR, Lee L, Hill R, Forstner G 1984 Colipase and lipase secretion in childhood onset pancreatic insufficiency. Delineation of patients with steatorrhea secondary to relative colipase deficiency. Gastroenterology $86: 1-7$

20. Gaskin K, Durie P, Corey M, Wei P, Forstner G 1982 Evidence for a primary defect of pancreatic bicarbonate secretion in cystic fibrosis. Pediatr Res 16:554-557

21. Dyck WP 1967 Titremetric measurements of fecal trypsin and chymotrypsin in cystic fibrosis with pancreatic insufficiency. Am J Dig Dis 12:310-317

22. Fomon SJ, Ziegler ER, Thomas LN, Jensen RL, Filer LJ 1970 Excretion of fat by normal full-term infants fed various milks and formulas. Am J Clin Nutr 23:1299-1313

23. Corey ML 1980 Longitudinal studies in cystic fibrosis. in: Perspectives in cystic fibrosis. In: J Sturgess (ed) Proceedings of the Eighth International Congress in Cystic Fibrosis. Imperial Press Ltd., Mississauga, pp 246-255

24. SAS Users Guide: Statistics 1982 SAS Institute, Cary, NC

25. Gaskin K, Gurwitz D, Durie P, Corey M, Levison H, Forstner G 1982 Improved respiratory prognosis in patients with cystic fibrosis with normal fat absorption. J Pediatr 100:857-862

26. Heeley AF, heeley ME, Richmond SWJ 1983 The value of blood trypsin measured by RIA in the early diagnosis of cystic fibrosis. In: Albertini A, Crosignani S (eds) Progress in Pediatric Medicine. Elsevier Press, Amsterdam, pp 202-207

27. Taussig LM, Boat TF, Dayton D 1983 Neonatal screening for Cystic Fibrosis: position paper. Pediatrics $72: 741-745$

28. Kopelman H, Durie P, Gaskin K, Weizman Z, Forstner G 1985 Pancreatic fluid secretion and protein hyperconcentration in cystic fibrosis. $\mathrm{N}$ Engl J Med 312:329-334

29. Ho JJL, Rothman SS 1982 Nature of flow dependence of protein secretion by the exocrine pancreas. Am J Physiol 242:932-39

30. Kopito L, Shwachman H 1976 The pancreas in cystic fibrosis: chemical composition and comparative morphology. Pediatr Res 10:742-749

31. Shwachman H, Lebenthal E, Khaw K-T 1975 Recurrent acute pancreatitis in patients with cystic fibrosis with normal pancreatic enzymes. Pediatrics 55:86-95

32. Brodrick JW, Geokas MC, Largman C, Fassett M, Johnson JH 1979 Molecular forms of immunoreactive pancreatic cationic trypsin in pancreatitis patient sera. Am J Physiol 237:E474-80

33. Durie PR, Forstner GG, Gaskin KJ, Weizman Z, Kopelman HR, Ellis L, Largman C 1985 Elevated serum immunoreactive pancreatic cationic trypsinogen in acute malnutrition: Evidence of pancreatic damage. $J$ Pediatr $106: 233-38$

34. Borgstrom A, Ohlsson K 1980 Studies on the turnover of endogenous cathodal trypsinogen in man. Eur J Clin Invest 20:344-47 